AperTO - Archivio Istituzionale Open Access dell'Università di Torino

\title{
Effects of metastability on hydrogen sorption in fluorine substituted hydrides
}

\section{This is the author's manuscript}

Original Citation:

Availability:

This version is available http://hdl.handle.net/2318/151490

since 2016-01-02T21:53:04Z

Published version:

DOI:10.1016/j.jallcom.2014.01.028

Terms of use:

Open Access

Anyone can freely access the full text of works made available as "Open Access". Works made available under a Creative Commons license can be used according to the terms and conditions of said license. Use of all other works requires consent of the right holder (author or publisher) if not exempted from copyright protection by the applicable law. 


\section{Elsevier Editorial System(tm) for Journal of Alloys and Compounds Manuscript Draft}

Manuscript Number: JALCOM-D-13-04483R1

Title: Effects of metastability on hydrogen sorption in fluorine substituted hydrides

Article Type: Supplement: ISMANAM 2013

Keywords: Thermodynamic modelling; metal hydrides; phase diagrams; hydrogen absorbing materials; hydrogen storage

Corresponding Author: Prof. Marcello Baricco,

Corresponding Author's Institution: NIS Centre of Excellence

First Author: Eugenio R Pinatel, Dr.

Order of Authors: Eugenio R Pinatel, Dr.; Marta Corno, Dr.; Piero Ugliengo, Prof.; Marcello Baricco, Prof.

Abstract: In this work ab initio calculations and Calphad modelling have been coupled to describe the effect of fluorine substitution on the thermodynamics of hydrogenation-dehydrogenation in simple hydrides ( $\mathrm{NaH}, \mathrm{AlH} 3$ and $\mathrm{CaH} 2)$. These example systems have been used to discuss the conditions required for the formation of a stable hydride-fluoride solid solution necessary to obtain a reversible hydrogenation reaction. 


\section{Prime Novelty Statement}

To,

The Editor of the ISMANAM 2013 special issue

of Journal of Alloys and Compounds

- TITLE

Effects of metastability on hydrogen sorption in fluorine substituted hydrides

- $\quad$ AUTHORS

Eugenio R. Pinatel,

Marta Corno,

Piero Ugliengo,

Marcello Baricco

- CORRESPONDING AUTHOR

Prof. Marcello BARICCO

Dipartimento di Chimica and NIS

Universita' di Torino

Via P.Giuria, 9

I-10125 TORINO (Italy)

Tel. + 390116707569

Mob. +393667877947

Fax. + 390116707855

e-mail: marcello.baricco@unito.it

- $\quad$ PRIME NOVELTY STATEMENT

In the submitted manuscript, we are reporting new results obtained coupling ab initio calculations with Calphad modeling. The goal is to describe the effect of fluorine substitution on the thermodynamics of hydrogenation-dehydrogenation in simple hydrides. $\mathrm{NaH}-\mathrm{NaF}, \mathrm{CaH} 2-$ $\mathrm{CaF} 2$ and AlH3-AlF3 systems have been used as examples to describe the conditions required for the formation of a stable hydride-fluoride solid solution. Parameters necessary to obtain a reversible sorption reaction have been discussed.

- $\quad$ AUTHORSHIP STATEMENT

The submission of the manuscript has been approved by all co-authors

- $\quad$ Estimated WORD COUNT

3400 words ( $2320+$ figures $4 \times 250+$ equations $2 * 40$ words)

Yours Faithfully, 


\section{Prof. Marcello BARICCO}

Dipartimento di Chimica and NIS

Universita' di Torino

Via P.Giuria, 9

I-10125 TORINO (Italy)

Tel. + 390116707569

Mob. +39 3667877947

Fax. + 390116707855

e-mail: marcello.baricco@unito.it

Web: momo.ch.unito.it, www.nis.unito.it 


\section{Reply to referee's comments}

The authors acknowledge the referee for useful comments. In the following, specific answers are provided.

\section{General Comments}

The manuscript reports on modelling studies (ab-initio and CALPHAD) applied to fluorine-substituted metal hydrides. The aim is to investigate how the stability of the hydride-fluoride solid solution affects the thermodynamics and reversibility of the hydrogen desorption and absorption. Anion substitution in hydrogen storage materials has recently attracted a lot of interest as a way to destabilize hydrides which are too stable for hydrogen storage applications. The approach presented in this contribution is therefore actual and up-to-date, and further extends the general understanding of how the thermodynamics of hydrogen storage materials can be tailored.

The manuscript is clear and well organized. The results are discussed properly and compared with relevant literature data. The English is in most parts satisfactory, but it could be improved in a few instances (see detailed comments). The results presented in the paper are interesting and relevant to hydrogen storage and metastable materials. The paper can be therefore accepted for publications after minor revision (see comments below).

*) Introduction. The authors cite relevant articles related to anion substitution in hydrides. However, they do not cite the first paper which introduced the concept of anion substitution and showed its effect on the thermodynamics of hydrides (Brinks et al, J. Phys Chem C 112, 2008, 5658-5661). The authors should include this reference in the introduction.

Suggested reference has been introduced in the text.

*) Modelling. Please provide reference for Eq. (2)

A reference for Eq. (2) has been provided.

*) As mention in the general comments the English can be improved in few cases. For example, the last sentence of page 1: "Considering a too stable hydride...." This sentence is too long and confusing. Please revise.

English has been revised. The last sentence of page 1 has been shortened. 


\title{
Effects of metastability on hydrogen sorption in fluorine substituted hydrides
}

\author{
E.R. Pinatel, M. Corno, P. Ugliengo, M. Baricco \\ Dipartimento di Chimica, Università di Torino and NIS, Torino, Italy
}

\begin{abstract}
Abstact
In this work ab initio calculations and Calphad modelling have been coupled to describe the effect of fluorine substitution on the thermodynamics of hydrogenation-dehydrogenation in simple hydrides $\left(\mathrm{NaH}, \mathrm{AlH}_{3}\right.$ and $\left.\mathrm{CaH}_{2}\right)$. These example systems have been used to discuss the conditions required for the formation of a stable hydride-fluoride solid solution necessary to obtain a reversible hydrogenation reaction.
\end{abstract}

\section{Introduction}

Hydrogen storage is probably the bottleneck towards a sustainable carbon-free economy. Among various options, hydrogen storage in the solid state has been widely investigated in recent years [1]. In order to release or uptake hydrogen at ambient conditions, hydrogen storage materials require an enthalpy of hydrogenation around $35-40 \mathrm{~kJ} \mathrm{~mol}_{\mathrm{H} 2}{ }^{-1}[2]$. However, among known hydrides, no one shows reasonable kinetics and gravimetric density coupled with this thermodynamic requirement. As a consequence, several strategies have been developed to modify the thermodynamic properties of existing materials with high hydrogen contents [3]. In particular, substitution of hydrogen with other anions has been considered in recent works [4-10]. Among them, fluorine is often selected as a substituent, because of the similarity in size between $\mathrm{F}^{-}$and $\mathrm{H}^{-}$. Moreover, fluorides are usually extremely stable compounds, hence fluorine is not released in the gas phase and lost during the dehydrogenation. The concept of fluorine substitution in hydrides is described in figure 1. In the case of a too stable hydride, the aim is to reduce its stability. This can be obtained through the formation of a solid solution with a positive enthalpy of mixing. In this way, the dehydrogenation enthalpy for the substituted material $(x>0)$ will be 
lower than that of the pure hydride $(\mathrm{x}=0)$, leading to the desired thermodynamic properties. On the other hand, it is possible to stabilize a not enough stable hydride upon the creation of a solid solution with a negative enthalpy of mixing. The magnitude of the stabilization-destabilization is directly related to the value of the enthalpy of mixing for the selected level of substitution. Substituents are often selected on the basis of an initial guess, depending on the expected chemical behaviour. However, several attempts of mixing failed because the solid solution is metastable with respect to the physical mixture of pure hydride and fluoride, so that the target hydrogenation reaction is not thermodynamically favoured.

In the present work, thermodynamic models usually adopted in the Calphad method [11] will be used to describe the fluorine substitution in hydrides. In particular, the conditions leading to the formation of a stable solid solution, required for the reversibility of the hydrogen sorption reactions, will be discussed considering simple hydrides as example systems. In order to describe the investigated systems $\left(\mathrm{NaH}-\mathrm{NaF}, \mathrm{AlH}_{3}-\mathrm{AlF}_{3}\right.$ and $\left.\mathrm{CaH}_{2}-\mathrm{CaF}_{2}\right)$, ab initio calculations will be coupled with the Calphad approach [11]. The necessary thermodynamic conditions and possible limitations will be outlined.

\section{Modelling}

Ab initio calculations were carried out with the periodic CRYSTAL09 code $[12,13]$ using localized basis set functions of polarized double- $\zeta$ quality and DFT GGA Hamiltonian (PBE[14]). Phonons at $\Gamma$ point in the harmonic approximation were computed by diagonalizing the associated mass-weighted Hessian matrix to derive the thermodynamic functions $[15,16]$. As customary for the Calphad approach, the pure elements in their stable phases at $298.15 \mathrm{~K}$ and $101325 \mathrm{~Pa}$ were chosen as reference state. The gas mixture was considered as ideal including, for each system, all the compounds available in the SGTE substance database [17]. When present, the liquid phase was described as a solution of hydride and fluoride according to the Redlich- 
Kister expansion [18] using only binary interaction parameters already reported in literature [1921].

The solid solutions between hydrides and fluorides were described with two sublattices: the first occupied by the metal and the second occupied by $\mathrm{H}$ and F. According to this description, a single atom of hydrogen can be substituted by an atom of fluorine. Functions for stable pure hydrides and fluorides end-members were taken from the SGTE substance database [17]. The Gibbs free energy (GFE) difference between the metastable end members, $G^{\mathrm{m}}$, e.g. the hydride with the structure of the fluoride and vice versa, and the stable one, $G^{\mathrm{s}}$, was modelled as

$\Delta G^{\mathrm{m}-\mathrm{s}}=G^{\mathrm{m}}-G^{\mathrm{s}}=\Delta H^{\mathrm{m}-\mathrm{s}}-\mathrm{T} \cdot \Delta S^{\mathrm{m}-\mathrm{s}}$

where $\Delta H^{\mathrm{m}-\mathrm{s}}$ and $\Delta S^{\mathrm{m}-\mathrm{s}}$ are the difference in enthalpy and entropy between the metastable and the stable structures of the compound, estimated using ab initio calculations. The GFE of mixing for solid solutions, $\Delta G_{\mathrm{mix}}$, has been modelled according to the following equation [11]:

$\Delta G_{\text {mix }}=\mathrm{x} \cdot(1-\mathrm{x}) \cdot\left({ }^{0} \mathrm{~L}+(\mathrm{x}-(1-\mathrm{x})) \cdot{ }^{1} \mathrm{~L}\right)+\mathrm{nRT} \cdot(\mathrm{x} \cdot \ln (\mathrm{x})+(1-\mathrm{x}) \cdot \ln (1-\mathrm{x}))$

where $\mathrm{R}$ is the gas constant, $\mathrm{n}$ is the number of hydrogen-fluorine atoms for each metal atom, $\mathrm{x}$ is the fraction of fluoride and ${ }^{0} \mathrm{~L}$ and ${ }^{1} \mathrm{~L}$ are interaction parameters.

Since the thermal entropy of mixing, i.e. that computed from frequency values for a given configuration, estimated with ab initio calculations is negligible with respect to the configurational entropy (that is considered ideal, $\Delta \mathrm{S}_{\mathrm{id}}$ ), no temperature dependence was considered for ${ }^{0} \mathrm{~L}$ and ${ }^{1} \mathrm{~L}$. Therefore, these parameters were evaluated considering only the values of $\Delta H_{\text {mix }}$ as a function of composition estimated by ab initio calculations. 
3. Results and discussion

Since the reversibility of the hydrogenation/dehydrogenation reactions is one of the main requirements for a practical application of a material in a hydrogen tank, issues related to cycling will be addressed in the following. Firstly, the necessary conditions for the stability of a single solid solution between hydride and fluoride will be addressed. Indeed, if the solid solution is not stable, cycling the material will likely result in the disproportiation into two separate phases. Finally, the possible behaviour of the GFE of various phases during cycling will be described. Concerning the stability of the solid solution, three different cases were identified:

(a) hydride and fluoride with the same structure and negative $\Delta G_{\text {mix }}$

(b) hydride and fluoride with the same structure and positive $\Delta G_{\text {mix }}$

(c) hydride and fluoride with different structures

An example of case (a) is the NaH-NaF mixture. Both the hydride and the fluoride show a cubic structure and the enthalpy of mixing predicted by ab initio calculations is slightly negative (around $-2 \mathrm{~kJ} \mathrm{~mol}^{-1}$ ), as shown in figure $2 \mathrm{a}$. The optimized mixing parameters for this solid solution are ${ }^{0} \mathrm{~L}=-5.45 \mathrm{~kJ} \cdot \operatorname{mol}_{\mathrm{H} 2}{ }^{-1}$ and ${ }^{1} \mathrm{~L}=-1.75 \mathrm{~kJ} \cdot \operatorname{mol}_{\mathrm{H} 2}{ }^{-1}$. Because of the negative $\Delta G_{\text {mix }}$, in the low temperature region of the $\mathrm{NaH}-\mathrm{NaF}$ pseudo binary phase diagram (figure $2 \mathrm{~b}$ ) a single solid solution is obtained. If the temperature is increased, the solid solution releases gaseous $\mathrm{H}_{2}$ and leaves liquid $\mathrm{Na}$, which remains in equilibrium with a cubic solid solution containing more fluorine than the average composition. It has to be noticed that the equilibrium temperature for this reaction increases upon fluorine substitution, confirming that the dehydrogenation temperature can be modified using this approach. Actually, $\mathrm{NaH}$ is a rather stable hydride $\left(\Delta \mathrm{H}_{\mathrm{dec}}=113 \mathrm{~kJ} \mathrm{~mol}_{\mathrm{H} 2}^{-1}\right)$, so the formation of a solid solution with a negative enthalpy of mixing leads to a further stabilization of the system, increasing the equilibrium decomposition temperature. 
An example of case (b) is the $\mathrm{AlH}_{3}-\mathrm{AlF}_{3}$ mixture. $A b$ initio calculations gave a value of $\Delta H_{\text {mix }}=$ $15.8 \mathrm{~kJ} \mathrm{~mol}^{-1}$ for a level of substitution $\mathrm{x}=0.5$ [7], as reported in figure $2 \mathrm{c}$. Considering this value of $\Delta H_{\text {mix }}$, also $\Delta G_{\text {mix }}$ will be strongly positive. As a result, mixing between the hydride and fluoride is prevented at room temperature and, since aluminium hydride is not stable at ambient conditions, $\mathrm{AlF}_{3}$, pure aluminium and gaseous hydrogen are reported as stable phases at room temperature (figure 2d), as also confirmed by experiments [9]. At higher temperatures, allotropic transformation of $\mathrm{AlF}_{3}$ and melting of $\mathrm{Al}$ are predicted.

In general, if the contribution of a positive $\Delta H_{\text {mix }}$ to $\Delta G_{\text {mix }}$ is more relevant than $-T \Delta S_{i d}$, two different solid solutions (hydrogen rich and fluorine rich) will be in equilibrium. The solubility limits of these solid solutions will be lower for higher values of the $\Delta H_{\text {mix }}$. As a consequence, if $\Delta H_{\text {mix }}$ is strongly positive, the solid solutions show an extremely small solubility limit and will not be stable for relevant level of substitution, strongly reducing tuning effects on hydrogenation reactions.

In case (c), two different solid solutions have to be described. One with the fluoride structure and the second one with the hydride structure. Considering as an example the $\mathrm{CaH}_{2}-\mathrm{CaF}_{2}$ system, an orthorhombic (hydride structure) and a cubic (fluoride structure) solid solution have been modelled [22]. As shown in figure 2e, according to ab initio calculations, the enthalpy of mixing in the cubic solid solution is slightly negative, whereas a positive value is calculated for the orthorhombic one. From the Calphad assessment of the enthalpy data obtained from ab initio calculations, the following interaction parameters have been obtained: ${ }^{0} \mathrm{~L}_{\text {ortho }}=10.15,{ }^{1} \mathrm{~L}_{\text {ortho }}=3.47$, ${ }^{0} \mathrm{~L}_{\text {cubic }}=-2.95$ and ${ }^{1} \mathrm{~L}_{\text {cubic }}=0.19 \mathrm{~kJ} \cdot \mathrm{mol}^{-1}$. Considering the orthorhombic solid solution, even if the calculated $\Delta H_{\text {mix }}$ is positive, because of the entropic contribution to the GFE, an appreciable solubility of $\mathrm{F}$ into $\mathrm{CaH}_{2}$ is calculated in the low temperature region of the pseudo binary phase diagram (figure 2f). On the other hand, because of the occurrence of a negative enthalpy of mixing, the cubic solid solution shows a wide range of solubility. 
It is worth to note that the free energy difference between cubic and orthorhombic $\mathrm{CaH}_{2}$ is rather small $\left(\Delta H^{\mathrm{m}-\mathrm{s}}=6.8 \mathrm{~kJ} \cdot \mathrm{mol}_{\mathrm{H} 2}{ }^{-1}\right.$ and $\left.\Delta S^{\mathrm{m}-\mathrm{s}}=0.3 \mathrm{~J} \cdot \mathrm{mol}_{\mathrm{H} 2}{ }^{-1} \cdot \mathrm{K}^{-1}\right)$, promoting the solubility of $\mathrm{H}$ into solid $\mathrm{CaF}_{2}$, as confirmed by experimental investigations [22, 23].

It is evident that, in the last case, the pseudo binary phase diagram shows two solid solutions with a miscibility gap, because the hydride and the fluoride have different structures. In order to obtain a reversible dehydrogenation reaction, compositions corresponding to the miscibility gap should be avoided. For that reason, the solubility limit of the solid solution with the structure of the hydride should be as high as possible. Two main contributions affect this solubility limit: the first one is related to the enthalpy of mixing, whereas the second one is related to the difference in lattice stability between the stable and the metastable fluoride (i.e. the fluoride with the structure of the hydride). The construction of the common tangent for a hypothetical hydride-fluoride mixture is reported in figure 3, considering two different values for the lattice stability of the metastable fluoride. All the other parameters for the solid solution $\left(\Delta \mathrm{G}_{\text {mix }}\right.$ in particular) were kept constant. In case A, the metastable end-member is slightly less stable then the fluoride, so that the solubility limit is rather high (point A in figure 3). In the case B, the metastable fluoride is much less stable than the equilibrium one. As a consequence, the solubility limit of the hydride solid solution (point B in figure 3) is considerably reduced. It can be concluded that, if the hydride and the fluoride do not share the same structure, a negative value of $\Delta \mathrm{G}_{\text {mix }}$ is not sufficient to obtain a high solubility limit, but it is also necessary that the fluoride with the structure of the hydride is only slightly less stable than the equilibrium fluoride.

Despite it is well established that, using ball milling and other synthesis techniques, several solid solutions (even if metastable) can be formed, in many cases they are not useful for practical applications. Indeed, after the first dehydrogenation, they cannot be formed again when an increase of hydrogen pressure is applied. To this purpose, it is interesting to consider a sketch of the GFE of the hydride-fluoride mixture under dehydrogenation (high $T$ and low $P$ ) and under 
hydrogenation (high $P$ and low $T$ ) conditions, as shown in figure 4. During hydrogen release, the GFE of dehydrogenation products is lower with respect to that of the as prepared material (upper part of figure 4). For the rehydrogenation reaction, the effect of a $\mathrm{H}_{2}$ pressure increase is the destabilization of the free energy of dehydrogenation products (lower part in figure 4). So, a driving force to form back the solid solution is developed, as shown by the thick arrow in figure 4. However, this reaction is in competition with the formation of the physical mixture of hydride and fluoride as separate phases, promoted by the corresponding driving force, as shown by thin arrow in figure 4. Given a certain composition, corresponding to the desired value of the enthalpy of dehydrogenation, the driving force for the formation of the solid solution should be higher than that for the formation of the physical mixture. These conditions, however, can be obtained only for a limited level of substitution, if $\Delta \mathrm{G}_{\mathrm{mix}}$ is negative and if the metastable fluoride is just barely less stable than the stable one. It is worth to note that, when the hydride and the fluoride share the same structure $\left(\Delta \mathrm{G}^{\mathrm{m}-\mathrm{s}}=0\right)$, the difference in stability between the end members turns out equal to zero, so that only the value of $\Delta \mathrm{G}_{\mathrm{mix}}$ becomes relevant for the formation of a stable solid solution.

\section{Conclusions}

Thermodynamic models have been used to describe the conditions for the stability of hydridefluoride mixtures useful for hydrogen storage applications. Considering fluorine substitution, it is worth noting that fluorides are usually extremely stable compounds, so that the release of fluorine and the evolution of fluoridric acid is prevented.

On the other hand, a drawback of anion substitution is that the hydrogen content is linearly reduced upon substitution. Therefore, a significant loss in hydrogen capacity has to be considered if a strong tuning effect (hence a relevant level of substitution) is required to obtain the desired enthalpy of hydrogenation. 
Moreover, the use of this approach to destabilize a too much stable hydride seems not feasible. In fact, if a strongly positive $\Delta H_{\text {mix }}$ is required, also the $\Delta G_{\text {mix }}$ is expected to be positive, leading to a metastable solid solution and to the disproportiation into two different phases upon cycling. On the contrary, the use of this approach to stabilize not enough stable hydrides seems more promising.

Finally it is important to note that one of the most relevant quantities to predict the possible formation of a stable solid solution is the difference in GFE between the stable and the metastable fluoride (or, more generally, fully substituted compound). This contribution, that can be easily estimated using ab initio calculations, can be extremely significant because the magnitude of $\Delta \mathrm{G}_{\text {mix }}$ is usually limited to few $\mathrm{kJ} \mathrm{mol}^{-1}$, whereas that due to the stability of the end-member can be much more relevant.

\section{Acknowledgments}

This work was supported by the FLYHY project (contract no. 226943) under the FP7 Program in the European Commission. 


\section{References}

[1] M. Hirscher, Handbook of Hydrogen Storage, Weinheim Wiley, 2010.

[2] S.V. Alapati, J.K. Johnson, D.S. Sholl, Identification of destabilized metal hydrides for hydrogen storage using first principles calculations, Journal of Physical Chemistry B, 110 (2006) 8769-8776.

[3] L.H. Rude, T.K. Nielsen, D.B. Ravnsbaek, U. Bosenberg, M.B. Ley, B. Richter, L.M. Arnbjerg, M. Dornheim, Y. Filinchuk, F. Besenbacher, T.R. Jensen, Tailoring properties of borohydrides for hydrogen storage: A review, Physica Status Solidi a-Applications and Materials Science, 208 (2011) 1754-1773.

[4] H.W. Brinks, A. Fossdal, B.C. Hauback, Adjustment of the stability of complex hydrides by anion substitution, Journal of Physical Chemistry C, 112 (2008) 5658-5661.

[5] L.H. Rude, E. Groppo, L.M. Arnbjerg, D.B. Ravnsbaek, R.A. Malmkjaer, Y. Filinchuk, M. Baricco, F. Besenbacher, T.R. Jensen, Iodide substitution in lithium borohydride, LiBH4-LiI, Journal of Alloys and Compounds, 509 (2011) 8299-8305.

[6] O. Zavorotynska, M. Corno, A. Damin, G. Spoto, P. Ugliengo, M. Baricco, Vibrational Properties of MBH4 and MBF4 Crystals $(\mathrm{M}=\mathrm{Li}, \mathrm{Na}, \mathrm{K})$ : A Combined DFT, Infrared, and Raman Study, Journal of Physical Chemistry C, 115 (2011) 18890-18900.

[7] L.H. Rude, O. Zavorotynska, L.M. Arnbjerg, D.B. Ravnsbaek, R.A. Malmkjaer, H. Grove, B.C. Hauback, M. Baricco, Y. Filinchuk, F. Besenbacher, T.R. Jensen, Bromide substitution in lithium borohydride, LiBH4-LiBr, International Journal of Hydrogen Energy, 36 (2011) 1566415672.

[8] L.H. Rude, Y. Filinchuk, M.H. Sorby, B.C. Hauback, F. Besenbacher, T.R. Jensen, Anion Substitution in $\mathrm{Ca}(\mathrm{BH} 4)(2)-\mathrm{CaI}$ : Synthesis, Structure and Stability of Three New Compounds, Journal of Physical Chemistry C, 115 (2011) 7768-7777.

[9] J.E. Fonnelop, M. Corno, H. Grove, E. Pinatel, M.H. Sorby, P. Ugliengo, M. Baricco, B.C. Hauback, Experimental and computational investigations on the AlH3/AlF3 system, Journal of Alloys and Compounds, 509 (2011) 10-14.

[10] M. Corno, E. Pinatel, P. Ugliengo, M. Baricco, A computational study on the effect of fluorine substitution in LiBH4, Journal of Alloys and Compounds, 509 (2011) S679-S683. [11] H.L. Lukas, S.G. Fries, B. Sundman, Computational Thermodynamics, Cambridge University Press, 2007.

[12] R. Dovesi, R. Orlando, B. Civalleri, C. Roetti, V.R. Saunders, C.M. Zicovich-Wilson, CRYSTAL: a computational tool for the ab initio study of the electronic properties of crystals, Zeitschrift Fur Kristallographie, 220 (2005) 571-573.

[13] R. Dovesi, V.R. Saunders, C. Roetti, R. Orlando, C.M. Zicovich-Wilson, F. Pascale, B. Civalleri, K. Doll, N.M. Harrison, I.J. Bush, P. D’Arco, M. Llunell, CRYSTAL2009 User's Manual, University of Torino, 2009.

[14] J.P. Perdew, K. Burke, M. Ernzerhof, Generalized gradient approximation made simple, Physical Review Letters, 77 (1996) 3865-3868.

[15] C.M. Zicovich-Wilson, F.J. Torres, F. Pascale, L. Valenzano, R. Orlando, R. Dovesi, Ab initio simulation of the IR spectra of pyrope, grossular, and andradite, Journal of Computational Chemistry, 29 (2008) 2268-2278.

[16] F. Pascale, C.M. Zicovich-Wilson, F.L. Gejo, B. Civalleri, R. Orlando, R. Dovesi, The calculation of the vibrational frequencies of crystalline compounds and its implementation in the CRYSTAL code, Journal of Computational Chemistry, 25 (2004) 888-897. 
[17] SGTE, Substances Database v 4.1, in.

[18] O. Redlich, A. Kister, Algebraic representation of thermodynamic properties and the classification of solutions, Indust. Eng. Chem., 40 (1948) 345-348.

[19] C. Qiu, S.M. Opalka, G.B. Olson, D.L. Anton, The Na-H system: from first-principles calculations to thermodynamic modeling, International Journal of Materials Research, 97 (2006) 845-853.

[20] S.J. Zhang, C. Brubaker, C. Jiang, M. Yang, Y. Zhong, Q.Y. Han, Z.K. Liu, A combined first-principles calculation and thermodynamic modeling of the F-K-Na system, Materials Science and Engineering a-Structural Materials Properties Microstructure and Processing, 418 (2006) 161-171.

[21] C.A. Qiu, G.B. Olson, S.M. Opalka, D.L. Anton, Thermodynamic evaluation of the Al-H system, Journal of Phase Equilibria and Diffusion, 25 (2004) 520-527.

[22] E.R. Pinatel, L.H. Rude, M. Corno, M. Kragelund, P. Ugliengo, T.R. Jensen, M. Baricco, Thermodynamic Tuning of Calcium Hydride by Fluorine Substitution, MRS Online Proceedings Library, 1441 (2012) 5-12.

[23] J.-F. Brice, A. Courtois, J. Aubry, Preparation de la solution solide hydrurofluoree CaF2$\mathrm{xHx}(0<\mathrm{x}<1,24)$ etude structurale par diffraction des rayons $\mathrm{X}$ et par diffraction des neutrons Journal of Solid State Chemistry, 24 (1978). 


\section{Highlights}

TITLE :Effects of metastability on hydrogen sorption in fluorine substituted hydrides AUTHORS : Eugenio R. Pinatel, Marta Corno, Piero Ugliengo and Marcello Baricco

\section{Highlights}

- Fluorine substitution in simple metal hydrides has been modeled.

- The stability of the $\mathrm{MH}_{(1-\mathrm{x})} \mathrm{F}_{\mathrm{x}}$ solid solutions has been discussed.

- Conditions for reversibility of sorption reactions have been suggested. 
Effects of metastability on hydrogen sorption in fluorine substituted hydrides

E.R. Pinatel, M. Corno, P. Ugliengo, M. Baricco

Figure captions

Figure 1 - Schematic representation of fluorine substitution approach. The enthalpy of mixing of the hydride-fluoride solid solution can be used to stabilize poorly stable hydrides (if positive) or to destabilize too stable hydrides (if negative) moving in the direction of the desired value: $35-40$ $\mathrm{kJ} \mathrm{mol}_{\mathrm{H} 2}{ }^{-1}$.

Figure 2 - Calculated values of the enthalpy of mixing for $\mathrm{MH}_{\mathrm{n}}-\mathrm{MF}_{\mathrm{n}}$ solid solution (left side, from top to bottom $\mathrm{M}=\mathrm{Na}, \mathrm{Al}, \mathrm{Ca}$ ). Values obtained from $a b$ initio calculations are shown as points and the Calphad modelling is reported as lines. $\mathrm{MH}_{\mathrm{n}}-\mathrm{MF}_{\mathrm{n}}$ pseudo-binary phase diagram (right side, from top to bottom $\mathrm{M}=\mathrm{Na}, \mathrm{Al}, \mathrm{Ca}$ ).

Figure 3 - Effect of the stability of the metastable end-member on the solubility limit of the hydride-structure solid solution. In the case A, the metastable end-member is slightly less stable then the equilibrium fluoride, in the case $\mathrm{B}$, the metastable fluoride is much less stable than the equilibrium one.

Figure 4 - Schematic representation of the different Gibbs free energy (GFE) levels for dehydrogenation (upper) and hydrogenation (lower) reactions of a hydride-fluoride solid solution. The GFE of the hydride-fluoride solid solution is reported as a continuous line, whereas the physical mixture of the reactants (hydride+fluoride) and products (metal+hydrogen+fluoride) are shown as a dotted and dashed line, respectively. Arrows show the driving force for the dehydrogenation (see text). 
Pinatel et al. Figure 1
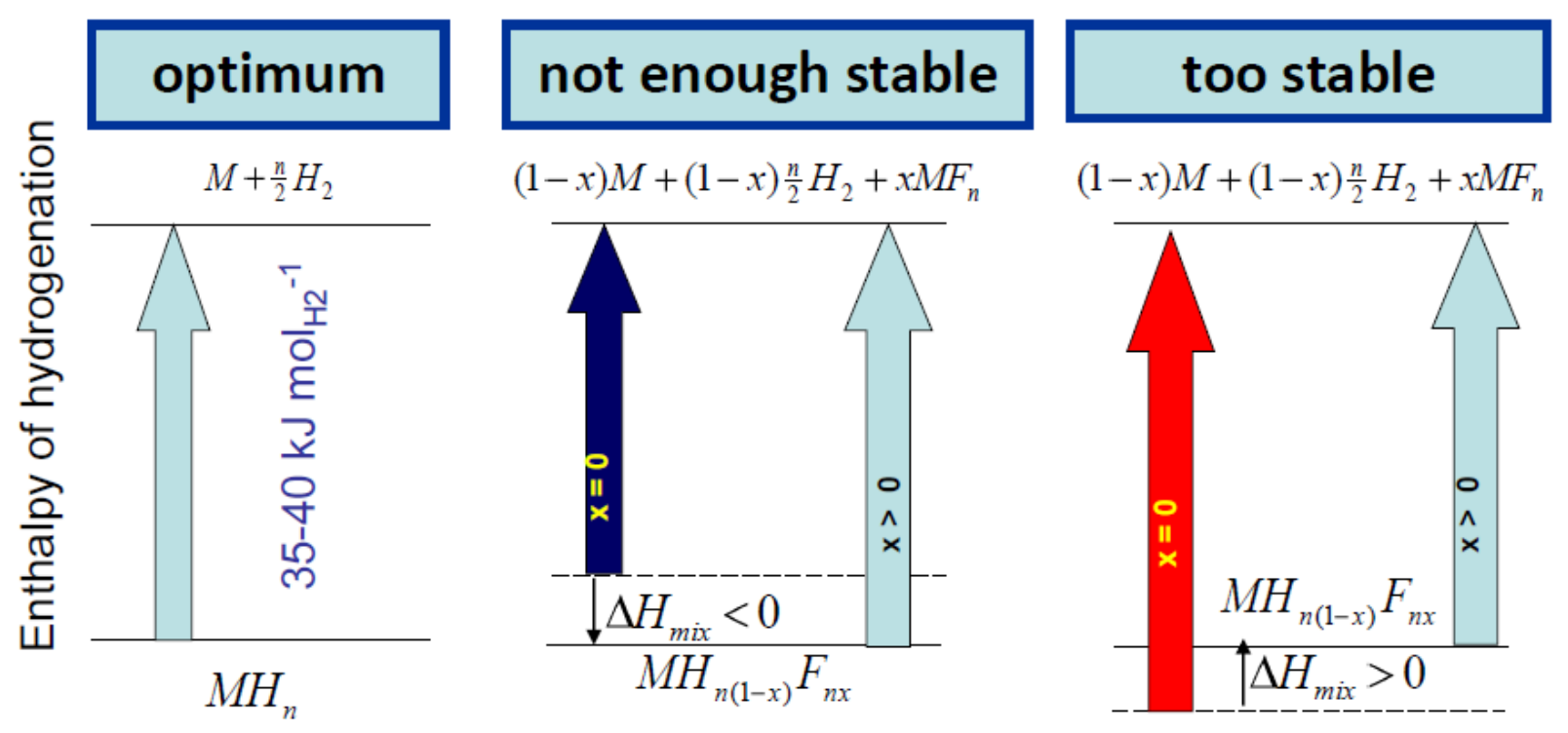
Pinatel et al. Figure 2

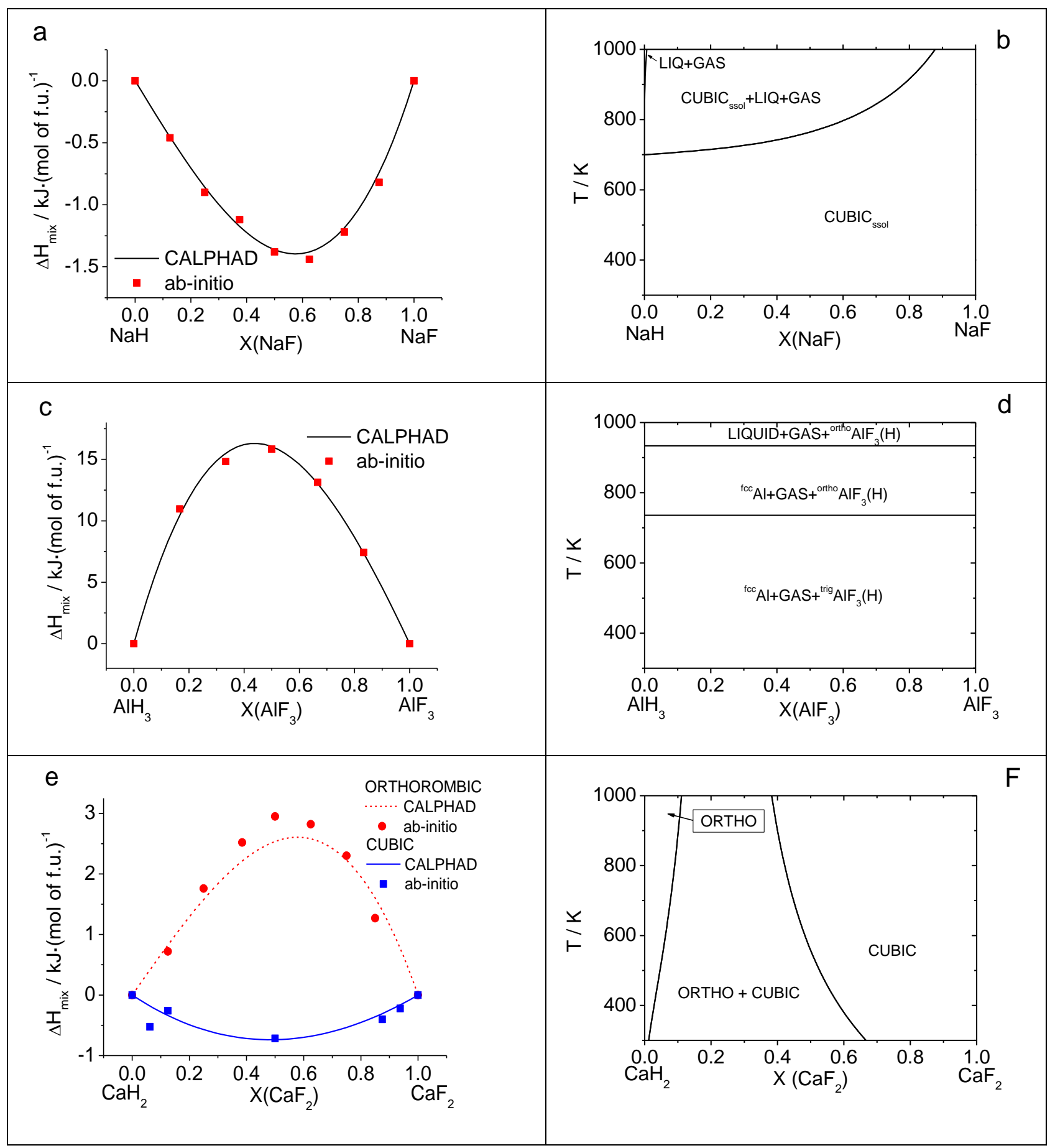


Pinatel et al. Figure 3

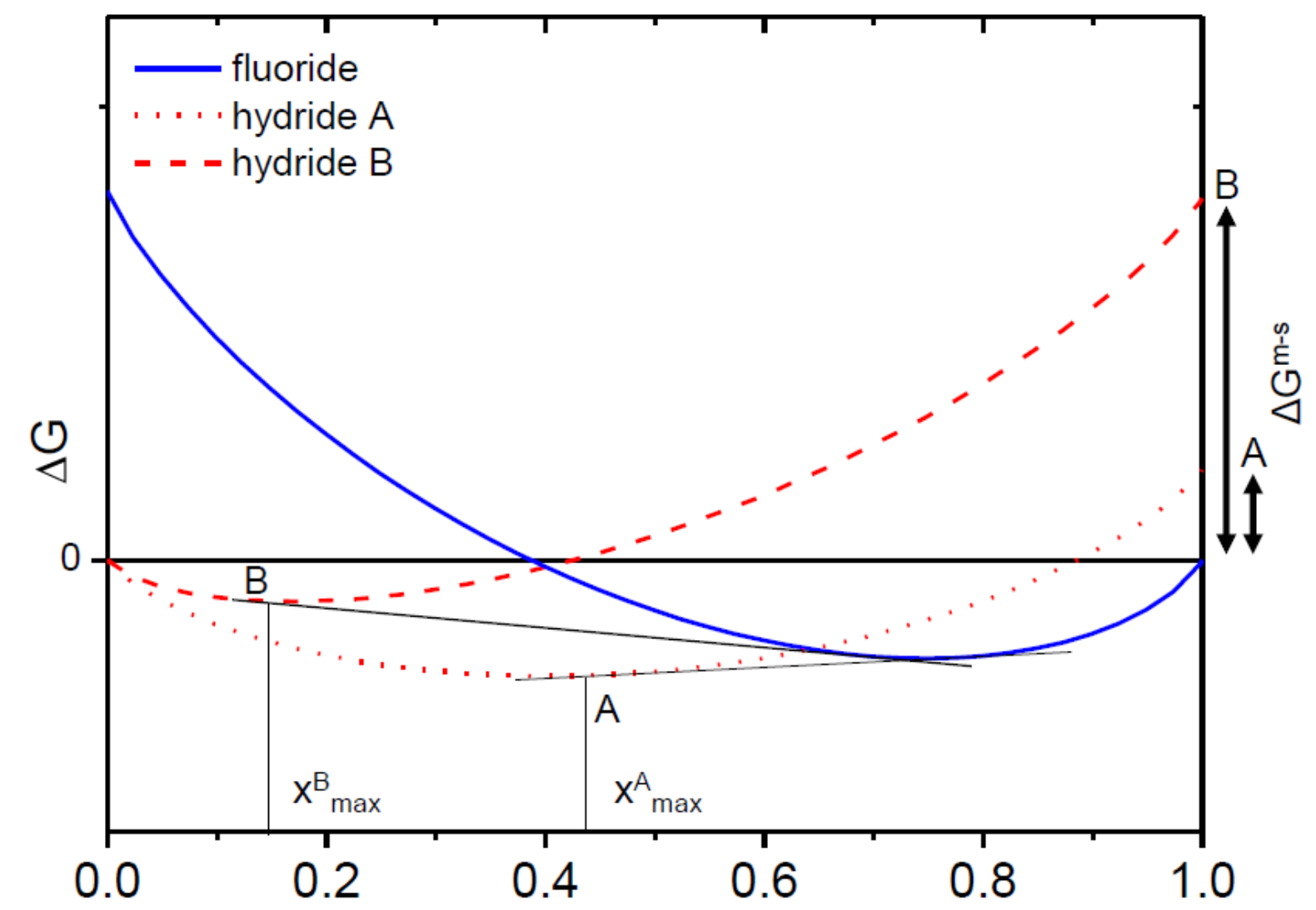

Hydride

$\mathrm{X}$ (fluoride)

Fluoride 


\section{High T \& low P}
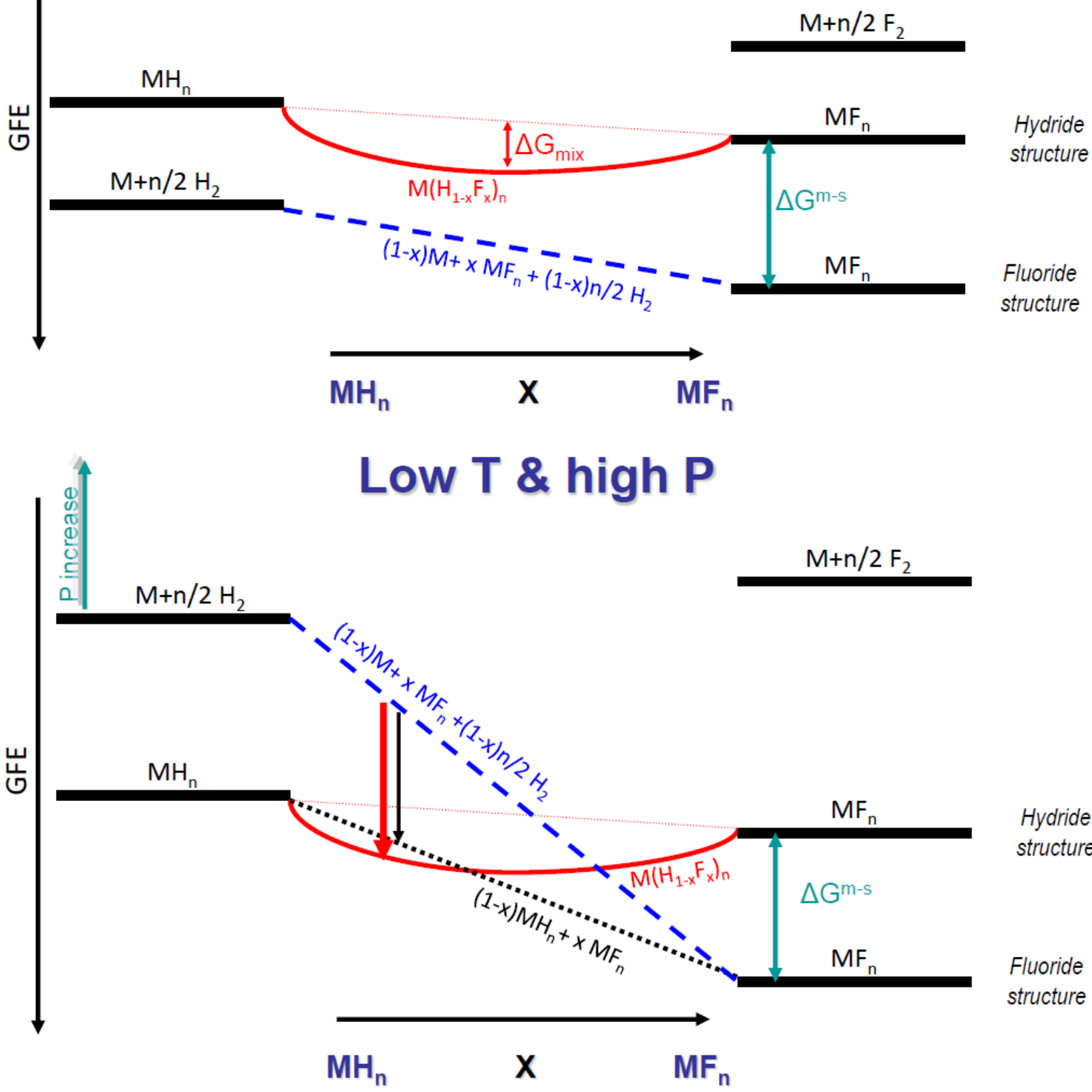